\title{
Determination of Polycyclic Aromatic Hydrocarbons in Water Using Nanoporous Material Prepared from Waste Avian Egg Shell
}

\author{
Abdulmumin A. Nuhu, ${ }^{1}$ Chanbasha Basheer, ${ }^{1,2}$ \\ Amjad Ashfaque Shaikh, ${ }^{3}$ and Abdul Rahman Al-Arfaj ${ }^{1}$ \\ ${ }^{1}$ Department of Chemistry, King Fahd University of Petroleum and Minerals (KFUPM), P.O. Box 1509, Dhahran 31261, Saudi Arabia \\ ${ }^{2}$ Center of Research Excellence in Nanotechnology, King Fahd University of Petroleum and Minerals, Dhahran 31261, Saudi Arabia \\ ${ }^{3}$ Department of Chemical Engineering, King Fahd University of Petroleum and Minerals (KFUPM), Dhahran 31261, Saudi Arabia
}

Correspondence should be addressed to Chanbasha Basheer, cbasheer@kfupm.edu.sa

Received 21 June 2012; Revised 13 August 2012; Accepted 17 August 2012

Academic Editor: Shuangxi Xing

Copyright (c) 2012 Abdulmumin A. Nuhu et al. This is an open access article distributed under the Creative Commons Attribution License, which permits unrestricted use, distribution, and reproduction in any medium, provided the original work is properly cited.

\begin{abstract}
For the first time a biocompatible calcium carbonate vateritic polymorph was recrystallized from eggshell waste and its application for the extraction of polycyclic aromatic hydrocarbons in water samples was demonstrated. This nanoporous calcium carbonate was used as sorbent in dispersive micro-solid-phase extraction method. In this approach $50 \mathrm{mg}$ of the calcium carbonate material having about $25 \mathrm{~nm}$ pores was placed in a $5 \mathrm{~mL}$ of water sample and ultrasonicated for $30 \mathrm{~min}$. The cloudy sample was centrifuged at $13500 \mathrm{rpm}$ for $2 \mathrm{~min}$. The aqueous layer was then discarded and the $\mathrm{CaCO}_{3}$ material was dabbed dry with a lint-free tissue. The analytes were then desorbed with $100 \mu \mathrm{L}$ of dichloromethane by ultrasonication for 5 min. Finally, the extract was analyzed by gas chromatography flame ionization detector. Experimental parameters affecting the extraction recoveries were optimized. Using optimum extraction conditions, calibration curves were linear with correlation coefficients of 0.9853 to 0.9973 over the concentration range of 0.05 to $30 \mathrm{ng} / \mathrm{mL}$. This method showed a detection limit as low as $0.004 \mathrm{ng} / \mathrm{mL}$ (at signal-to-noise ratio of 3). Performance of the dispersive micro-solid-phase extraction was compared with a previously optimized solid-phase extraction technique. The developed method displayed good extraction recoveries $(85 \pm 8-110 \pm 4 \%)$ with high enhancement factors (3881433 -fold) and good repeatability $(\%$ RSD $<13)$ and involved the use of minimal solvents. Analysis of seawater from Dammam Port revealed the presence of the analytes at concentrations between $0.15 \pm 0.01$ and $13.43 \pm 1.54 \mathrm{ng} / \mathrm{mL}$.
\end{abstract}

\section{Introduction}

In recent times, the search for new advanced materials has been the focus of numerous research interests. Due to their potential applicability, researchers are now dedicating much effort to the study of these materials, with continuous inspiration derived from nature through Biomimicry-a recent research area that seeks to understand and take inspiration from natural phenomena in order to solve human problems [1]. Of particular interest are the biomineralization processes by which living organisms produce minerals often to harden existing tissues. An example is the eggshell which is predominantly composed of calcium carbonate $\left(\mathrm{CaCO}_{3}\right)[1,2]$. In the field of analytical chemistry, great attention has been paid to nanoporous materials from different sources including
$\mathrm{CaCO}_{3}$ from waste avian eggshells. The electrostatic nature of $\mathrm{CaCO}_{3}$ particle [2] and its porous architecture make it a promising candidate as a solid sorbent for the extraction of polycyclic aromatic hydrocarbons (PAHs).

PAHs are ubiquitous pollutants that are found in different environmental matrices at different concentrations $[3,4]$. Significant accumulation of PAHs in the aquatic ecosystem had been caused by anthropogenic inputs like oil spills, sea navigation, urban runoff, water, and industrial wastes [5-7]. High concentrations of PAHs are found in marine coastal environment near cities and industrial plants [8]. Initially, concern about PAHs was only focused on their carcinogenic property $[9,10]$. Recently, however, searchlight has been beamed on their antagonism of hormonal functions and their potential effect on reproduction in humans, as well 

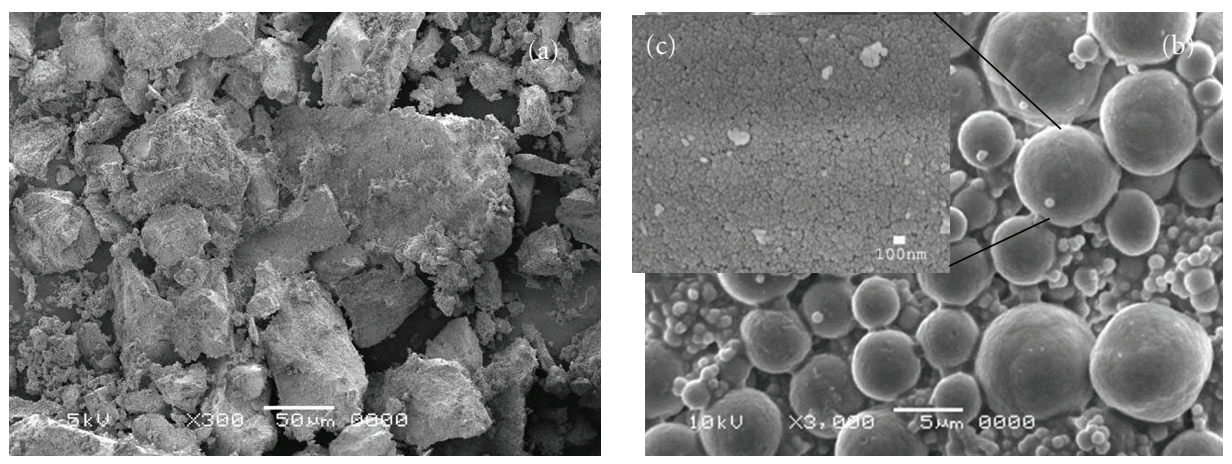

FIGURE 1: Scanning electron micrographs of (a) grinded powder of goose eggshell (b) recrystallized $\mathrm{CaCO}_{3}$ material and (c) nanoporous surface of a single-calcium carbonate vateritic ball.

as their ability to depress immune function [11]. These concerns have prompted both the World Health Organization (WHO) [12] and the United States Environmental Protection Agency (USEPA) [13] to formulate regulations for the protection of drinking and source water systems in order to safeguard the populace from such harmful pollutants, many of which are considered as potential carcinogens. For many superficial water systems, the European Union (EU) has set maximum admissible concentrations of $100 \mathrm{ng} / \mathrm{L}$ for both anthracene and fluoranthene, and $1200 \mathrm{ng} / \mathrm{L}$ for naphthalene [14].

Development of methodologies for the analysis of PAHs is, therefore, one of the important aspects of environmental analytical chemistry [15]. In this regard, on-line and offline solid-phase extraction (SPE) has been widely studied for trace analysis of PAHs $[15,16]$. It can be combined with gas chromatography-mass spectrometry (GC-MS) or gas chromatography-flame ionization detector (GC-FID). Unfortunately, due to their mainly nonpolar nature and adsorption onto walls of extraction vessels, PAHs are not very amenable for multistep extraction procedures such as SPE and liquid-liquid extraction [17-21]. These techniques may also involve large solvent volumes which may not be in consonance with good environment-conscious practices. A greener approach should involve fewer steps and minimization of solvent waste. Solvent minimization through the use of commercial polymeric materials for sorption in solid-phase microextraction (SPME) [22-24] and stir bar sorptive extraction (SBSE) $[25,26]$ have been attempted for the analysis of PAHs in water. However, these materials are often expensive. Alternative sorption material that can carry out this function at a lower cost and offer more convenience in handling would be a welcome development. The objectives of this study were, therefore, set to synthesize nanocrystal sorbent materials from waste egg shells and to apply these in the solvent minimization method of dispersive micro-solidphase extraction (D- $\mu$-SPE) with GC-FID for the analysis of selected PAHs in water.

\section{Experimental}

2.1. Preparation of Nanoporous $\mathrm{CaCO}_{3}$ Vateritic Polymorph. To prepare the nanoporous $\mathrm{CaCO}_{3}$ sorption material, waste avian egg shells from quails were dried and broken into small pieces. These pieces were then grinded and the coarse lump was treated with ammoniacal hypochlorite bleach solution (5\%) for about $15 \mathrm{~min}$ to remove the egg shell membrane. $10 \mathrm{~g}$ of clear, bleached egg shells were powdered and decalcified with $100 \mathrm{~mL}$ hydrochloric acid (2M) for $12 \mathrm{hrs}$. Vateritic calcium carbonate crystals were then grown from this solution using Weiner's vapor diffusion method $[27,28]$. Previously, vateritic balls of $\mathrm{CaCO}_{3}$ were observed during precipitation reaction in the presence of organic additives [29]. These balls were of high porosity and proved to be efficient in drug delivery [30]. The presence of inorganic and organic substances, such as magnesium ions and aspartic acid, may influence the growth of calcium carbonate and control its morphology [31, 32]. Hence, these substances can be used to adjust the porosity of the produced nanoporous material. Figure 1 shows the eggshell scanning electron micrographs before (a) and after crystallization (b). About $25 \mathrm{~nm}$ pores can be seen in the figure (c).

2.2. Reagents and Chemicals. Individual PAH standards (99.5\% purity) were purchased from Sigma (St. Louis, MO, USA). HPLC-grade solvents were from J. T. Baker, (NJ, USA). Ultrapure water was purified in a Milli-Q-water purification system (Millipore, Bedford, MA, USA). Standard working solution was prepared in methanol everyday using stock solution. All reagents and solvents used were of analytical or HPLC-grade unless otherwise mentioned. Seawater samples were collected from Dammam (Eastern province of Saudi Arabia) in Teflon jars in accordance with USEPA surface water sampling SOP (EPA, 1991) and analyzed on the same day. Methanol $(10 \%, \mathrm{v} / \mathrm{v})$ was added to these samples and mixed thoroughly in order to avoid adsorption of PAHs onto glassware.

\subsection{Dispersive Micro-Solid-Phase Extraction and Solid-Phase} Extraction. The D- $\mu$-SPE was carried out as follows: the nanoporous vateritic $\mathrm{CaCO}_{3}(50-\mathrm{mg})$ was first conditioned with dichloromethane (DCM) (for $5 \mathrm{~min}$ in ultrasonicator) and then placed in $5 \mathrm{~mL}$ water sample spiked with $10 \mu \mathrm{L}$ of the mixed PAHs solution ( $10 \mu \mathrm{g} / \mathrm{mL}$ of each compound $)$ in a $10 \mathrm{~mL}$ glass centrifuge vial. This was then ultrasonicated 
for $30 \mathrm{~min}$ and the resultant cloudy sample centrifuged at $13500 \mathrm{rpm}$ for $2 \mathrm{~min}$. The aqueous layer was discarded and the material was dabbed dry by placing it on a lint-free tissue to remove excess moisture. A $100 \mu \mathrm{L}$ of DCM was then added to the nanoporous calcium carbonate crystals and ultrasonicated for $15 \mathrm{~min}$ for analyte desorption. Finally, $2 \mu \mathrm{L}$ of DCM containing the desorbed analytes was injected into the GC-FID machine using autosampler. In order to avoid any carryover effects, each extraction was performed using a freshly prepared nanoporous vateritic $\mathrm{CaCO}_{3}$ material.

SPE experiment was performed based on previously optimized extraction conditions [33].

2.4. GC-FID Analysis. Determination of PAHs was carried out using Agilent GC 7890A. Chromatographic separation of the seven PAHs was accomplished with a DB-1 fused-silica capillary column $(30 \mathrm{~m} \times 0.32 \mathrm{~mm}$ I.D, $1 \mu \mathrm{m}$ film thickness $)$ from J\&W Scientific. Helium was used as carrier gas at a flow rate of $0.45 \mathrm{~mL} / \mathrm{min}$. Sample injection was in the splitless mode with an injection volume of $2 \mu \mathrm{L}$. The GC oven temperature program was optimized: initial temperature of $70^{\circ} \mathrm{C}$ was held for $2 \mathrm{~min}$ and then ramped at $10^{\circ} \mathrm{C} / \mathrm{min}$ to $220^{\circ} \mathrm{C}$. It was maintained at this temperature till the end of the run $(33 \mathrm{~min})$. The injection port temperature was set at $250^{\circ} \mathrm{C}$ and that of the FID detector was set at $300^{\circ} \mathrm{C}$. The hydrogen and air flow rates were set at $40 \mathrm{~mL} / \mathrm{min}$ and $400 \mathrm{~mL} / \mathrm{min}$, respectively.

\section{Results and Discussion}

The extraction mechanism for D- $\mu$-SPEis similar to SPME and SBSE. Preliminary studies were conducted to investigate the most appropriate solvents (DCM, toluene, methanol, and hexane) for conditioning nanoporous vateritic balls of $\mathrm{CaCO}_{3}$. Conditioning with organic solvent resulted in significant improvement in the extraction performance of the nanoporous $\mathrm{CaCO}_{3}$, probably due to improved wettability of the sorbent in the presence of the solvent. Other parameters that might influence the extraction efficacy of the procedure were investigated prior to using it for the determination of PAHs in real water samples. The objective of the optimization procedure was to obtain maximum analyte recovery and sensitive determination. The parameters investigated were extraction time, sample $\mathrm{pH}$, extraction solvent, and desorption time. All experiments were performed in replicates of three.

To optimize the effect of different extraction time on the efficacy of the method, experiment was performed by keeping all other conditions constant and varying the extraction time from 10 to $70 \mathrm{~min}$. Results are given in Figure 2; $30 \mathrm{~min}$ appeared to be the sufficient time that would allow optimal interaction between the PAHs and the nanoporous crystals. Increasing the extraction time beyond the $30 \mathrm{~min}$ resulted in negative to no apparent effect on most of the analytes. At longer extraction time ( $>30 \mathrm{~min})$, heat produced by the ultrasonication would negatively affect the D- $\mu$-SPE process. Hence $30 \mathrm{~min}$ was adopted during subsequent trials.

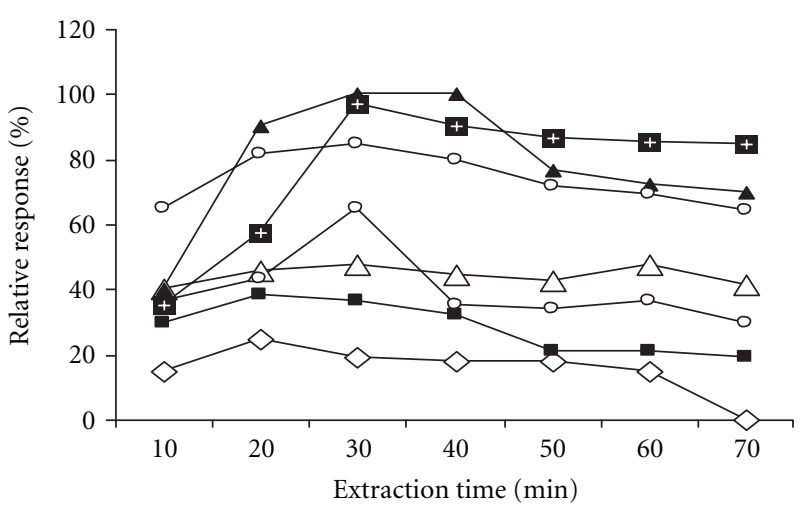

$$
\begin{array}{ll}
\checkmark \text { - Naphthalene } & - \text { Phenanthrene } \\
\rightarrow-\text { Biphenyl } & -+ \text { Pyrene } \\
\neg \text { Acenaphthene } & -\infty \text { Fluoranthene } \\
\rightarrow-\text { Fluorene } &
\end{array}
$$

Figure 2: Effect of extraction time on the relative response of seven PAHs at experimental conditions of $5 \mathrm{~mL}$ sample volume $(20 \mathrm{ng} / \mathrm{mL}), 5 \mathrm{~min}$ desorption in DCM $(100 \mu \mathrm{L})$ and $50 \mathrm{mg} \mathrm{CaCO} 3$ nanocrystals as sorbent.

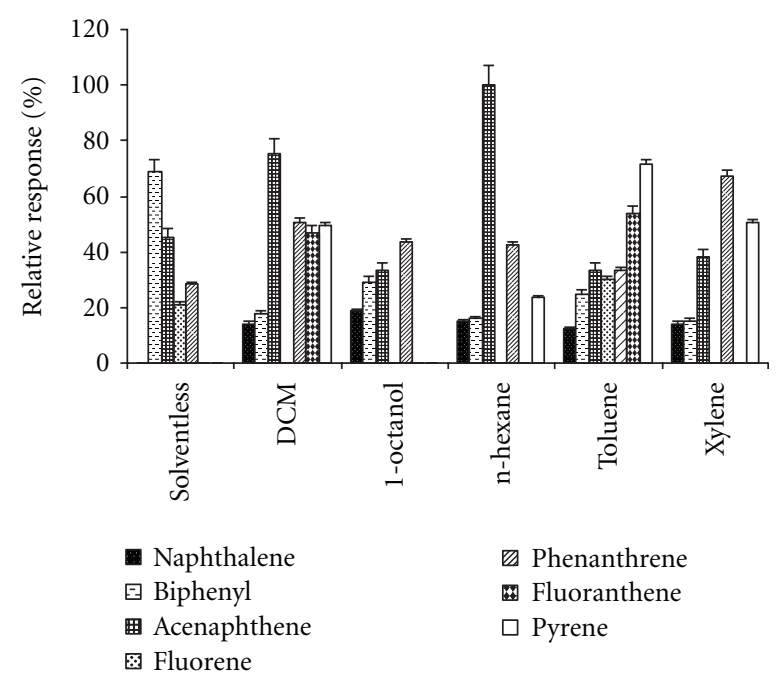

FIGURE 3: Effect of various conditioning solvents on the relative response of seven PAHs at experimental conditions of $5 \mathrm{~mL}$ sample volume $(20 \mathrm{ng} / \mathrm{mL}), 10 \mathrm{~min}$ ultrasonic extraction, $5 \mathrm{~min}$ desorption time, and $50 \mathrm{mg} \mathrm{CaCO}_{3}$ nanocrystals as sorbent.

Extraction was performed in the absence of any solvent and compared to the results obtained in the presence of five different conditioning solvents. The presence of solvent has significantly enhanced the extraction procedure. Although some compounds performed relatively better in other solvents, only toluene was able to extract all the seven analytes simultaneously as shown in Figure 3. Hydrophobic interaction [37] seems to govern the sorption of PAHs to the porous nanocrystals. The better performance of the extraction procedure with toluene might be due to its better facilitation of the interaction of these nonpolar analytes with the hydrophobic hollow spaces within the nanocrystals. Although both xylene and toluene contain an aromatic ring, 
TABLE 1: Method parameters using D- $\mu$-SPE and GC-FID for PAHs determination in water.

\begin{tabular}{|c|c|c|c|c|c|c|c|}
\hline PAHs & Slope \pm SD & Intercept \pm SD & $R^{2^{\mathrm{a}}}$ & $\mathrm{LOD}^{\mathrm{b}}(\mathrm{ng} / \mathrm{mL})$ & $\mathrm{LOQ}^{\mathrm{c}}(\mathrm{ng} / \mathrm{mL})$ & $\mathrm{EF}^{\mathrm{d}}$ & $\operatorname{RSD}(\%), n=3$ \\
\hline Naphthalene & $1.02 \pm 0.03$ & $4.79 \pm 0.13$ & 0.9953 & 0.022 & 0.073 & 1433 & 2.71 \\
\hline Biphenyl & $0.46 \pm 0.02$ & $6.23 \pm 0.31$ & 0.9857 & 0.012 & 0.04 & 567 & 4.88 \\
\hline Acenaphthene & $1.04 \pm 0.10$ & $11.02 \pm 1.10$ & 0.9853 & 0.008 & 0.027 & 968 & 9.96 \\
\hline Fluorene & $0.95 \pm 0.05$ & $10.48 \pm 0.62$ & 0.9939 & 0.01 & 0.033 & 682 & 5.65 \\
\hline Phenanthrene & $1.33 \pm 0.14$ & $6.64 \pm 0.72$ & 0.9939 & 0.008 & 0.027 & 839 & 11.21 \\
\hline Fluoranthene & $0.72 \pm 0.09$ & $97.57 \pm 10.70$ & 0.9950 & 0.006 & 0.02 & 1376 & 12.5 \\
\hline Pyrene & $0.64 \pm 0.64$ & $10.23 \pm 1.02$ & 0.9973 & 0.004 & 0.013 & 388 & 10.51 \\
\hline
\end{tabular}

${ }^{a}$ Coefficient of determination for $0.05-30 \mathrm{ng} / \mathrm{mL}$.

bLOD: limit of detection at $\mathrm{S} / \mathrm{N}=3$.

${ }^{\mathrm{c}} \mathrm{LOQ}$ : limit of quantitation at $\mathrm{S} / \mathrm{N}=10$.

${ }^{d}$ EF: enhancement factor (ratio of peak area for extracted sample relative to unextracted one).

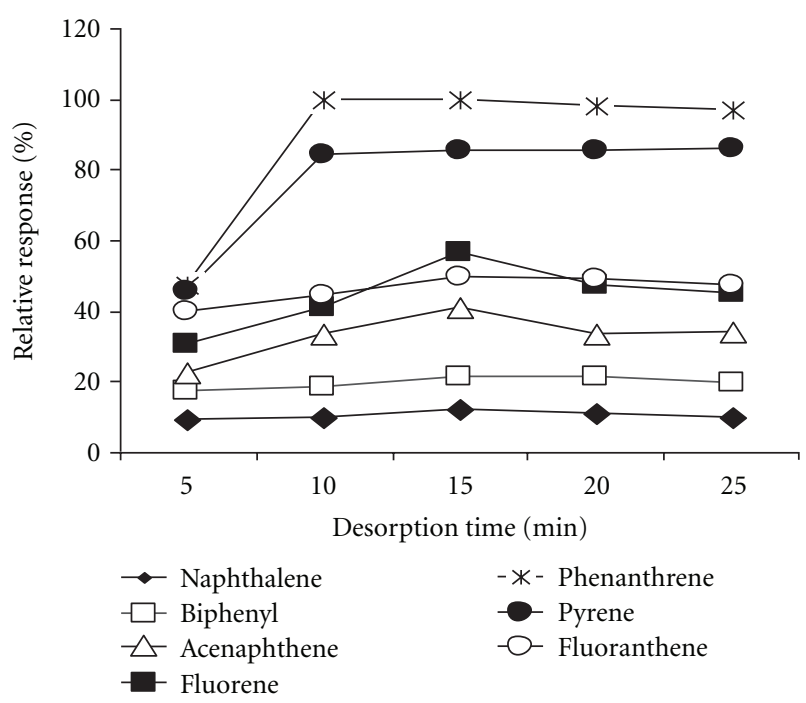

FIGURE 4: Effect of desorption time on the relative response of seven PAHs at experimental conditions of $5 \mathrm{~mL}$ sample volume $(20 \mathrm{ng} / \mathrm{mL}), 30 \mathrm{~min}$ extraction time, $50 \mathrm{mg} \mathrm{CaCO}_{3}$ nanocrystals as sorbent.

the latter solvent has lower viscosity which enabled it to have a better interaction with both the analytes and the hydrophobic pores of the sorbent. Toluene was then selected as conditioning solvent in subsequent experiments.

After the extraction, desorption was performed in $100 \mu \mathrm{L}$ of DCM at five different times: 5, 10, 15, 20 and 25 min. Figure 4 indicates no significant difference in the relative responses of biphenyl and naphthalene between 5 and $25 \mathrm{~min}$. However, both pyrene and phenanthrene were desorbed at the optimum time of $10 \mathrm{~min}$, while $15 \mathrm{~min}$ was necessary for acenaphthene, fluorine, and fluoranthene desorption. Consequently, 15 min was taken as desorption time in the remaining parts of this study.

Five $\mathrm{pH}$ values $(2,4,7,9$ and 12) were examined in order to study their effect on the D- $\mu$-SPE method. Results obtained show generally no significant difference in the peak areas of the analytes when the extraction procedure was performed at the acidic and basic $\mathrm{pH}$ values as compared to the neutral $\mathrm{pH}$. This indicates the absence of significant impact of $\mathrm{pH}$ on the analytes which may be explained from the lack of ionizable groups on the PAHs. As a result, all subsequent trials in this study were performed at neutral $\mathrm{pH}$. Nanoporous $\mathrm{CaCO}_{3}$ crystals are easily soluble at very low sample $\mathrm{pH}(<2)$.

3.1. Method Performance and Quantitative Analysis. Various performance criteria including enhancement factor (EF) of the extraction procedure (the ratio of peak areas for extracted sample relative to unextracted one), relative standard deviation (RSD, $n=3$ ); linearity and limit of detection (LOD) (at signal-to-noise ratio, $\mathrm{S} / \mathrm{N}=3$ ) were used to assess the performance of this method. Table 1 shows linearity of the detector response between the concentrations of 0.05 and $30 \mathrm{ng} / \mathrm{mL}$, with coefficient of determination ranging from 0.9853 to 0.9953 . The instrument responsivity was greatly enhanced by the high EF of the extraction method. In addition, the repeatability of this method is good as signified by RSD of $<13 \%$. LOD $(\mathrm{ng} / \mathrm{mL})$ values of the different analytes were obtained at $\mathrm{S} / \mathrm{N}$ of 3 , with pyrene having the lowest value of 0.004 . The LODs are low enough for the successful determination of the PAHs in water. For quantitative determination of the analytes, the limits of quantitation (LOQ) were estimated from $\mathrm{S} / \mathrm{N}$ equaled 10.

Characteristics of the $\mathrm{CaCO}_{3}$ nanocrystal-based $\mathrm{D}-\mu$ SPE-GC-FID method can be seen to compare favorably with previously reported techniques in the literature (Table 2). Extraction performance of $\mathrm{D}-\mu$-SPE is comparable with previously established microextraction techniques [34-36]. As shown in Figure 5, both D- $\mu$-SPE and SPE techniques showed comparable extractions performance. However, SPE required longer extraction time and huge amount of organic solvents. Table 3 shows the percentage recoveries of $\mathrm{D}-\mu$ SPE and SPE techniques spiked at the same concentrations $(5 \mathrm{ng} / \mathrm{mL}$ ). The percentage relative recoveries (ratio of the peak area for spiked seawater sample to that of spiked ultrapure water) indicate the absence of negative matrix effect. The optimized D- $\mu$-SPE-GC-FID method was successfully applied to the analysis of real water samples 
TABLE 2: $\mathrm{CaCO}_{3}$ nanoporous crystal-based D- $\mu$-SPE-GC-FID method characteristics as compared with literature.

\begin{tabular}{lccccccc}
\hline Method & SV $^{\mathrm{a}}$ & ET $^{\mathrm{b}}$ & LOD $(\mathrm{ng} / \mathrm{L})$ & \%RSD & RR $^{\mathrm{c}}$ & $N^{\mathrm{d}}$ & Reference $^{\mathrm{d}}$ \\
\hline IL-SPME-GC-MS $^{\mathrm{e}}$ & 10 & 40 & $4-5$ & $6.1-11.4$ & $80-110$ & 5 & {$[34]$} \\
SBSE-LC-FLD $^{\mathrm{f}}$ & 10 & 60 & $0.2-2$ & $4.7-13.5$ & $58-100$ & 15 & {$[35]$} \\
SPE-HPLC-UV $^{\mathrm{g}}$ & 20 & 20 & $5-40$ & $1-6$ & $94-106$ & 5 & {$[36]$} \\
D- $\mu$-SPE -GC-FID & 5 & 30 & $4-22$ & $2.7-12.5$ & $84-110$ & 7 & Present \\
\hline
\end{tabular}

a Sample volume $(\mathrm{mL})$.

${ }^{\mathrm{b}}$ Extraction time ( $\left.\mathrm{min}\right)$.

${ }^{\mathrm{c}}$ Relative recovery (\%).

${ }^{\mathrm{d}}$ Number of PAHs determined.

eNafion membrane-supported ionic liquid-solid phase microextraction (SPME) with GC-MS.

f Stir bar sorptive extraction (SBSE) and liquid chromatography (LC) with fluorescence detection.

gOnline SPME with LC and ultraviolet detection.

TABLE 3: Relative recoveries (\%RR) of D- $\mu$-SPE, SPE and the mean concentration of PAHs detected using D- $\mu$-SPE of real water analysis.

\begin{tabular}{lccc}
\hline PAHs & $\begin{array}{c}\text { \%RR of SPE } \\
5 \mathrm{ng} / \mathrm{mL} \text { spiked sample }\end{array}$ & $\begin{array}{c}\text { \%RR of D- } \mu \text {-SPE } \\
\text { ng/mL spiked sample }\end{array}$ & $\begin{array}{c}\text { Mean PAHs concentration detected from Dammam } \\
\text { real water samples }(\mathrm{ng} / \mathrm{mL}, n=10)\end{array}$ \\
\hline Naphthalene & $90 \pm 3$ & $92 \pm 3$ & $1.06 \pm 0.02$ \\
Biphenyl & $107 \pm 5$ & $110 \pm 4$ & $0.15 \pm 0.01$ \\
Acenaphthene & $84 \pm 8$ & $85 \pm 8$ & $1.90 \pm 0.18$ \\
Fluorene & $100 \pm 6$ & $104 \pm 5$ & $0.36 \pm 0.02$ \\
Phenanthrene & $90 \pm 10$ & $92 \pm 10$ & $3.22 \pm 0.33$ \\
Fluoranthene & $86 \pm 10$ & $87 \pm 10$ & $13.43 \pm 1.54$ \\
Pyrene & $94 \pm 10$ & $96 \pm 10$ & $0.43 \pm 0.04$ \\
\hline
\end{tabular}

(with salinity between 38.35 and 41.45 part per thousand) from Dammam Port. Ten selected stations were sampled around the Dammam Port. Four stations were located inside the port operational area and two each one in either side of the port. Two stations were sampled inside the shipping lane. This port is the main gateway through which cargoes from all over the world enter the Eastern and Central Provinces of the Kingdom. The port is fully self-sufficient with mechanical and marine workshops, water treatment plants, and about 39 berths. It is one of the busiest ports in Saudi Arabia. Around the port, artisan and small fishing boats are operated for both commercial and recreational purposes. The nearby Dammam Corniche is considered to be highly polluted with sewage discharges and other inputs from agricultural and rain waters. PAHs concentrations between $0.15 \pm 0.01$ and $13.43 \pm 1.54 \mathrm{ng} / \mathrm{mL}$ were found (Table 3).

\section{Conclusion}

Nanoporous polymorphic crystals of $\mathrm{CaCO}_{3}$ were used as sorbent and were applied in the dispersive micro-solidphase extraction of selected PAHs as target analytes. After separation of the analytes on gas chromatography, they were successfully quantified with external calibration using flame ionization detection. Different factors controlling the extraction procedures were investigated. Results have shown that in addition to solvent type, extraction and desorption time could have significant effect on the method performance. Comparison results have shown that this method could serve as a less costly and more viable alternative to other techniques

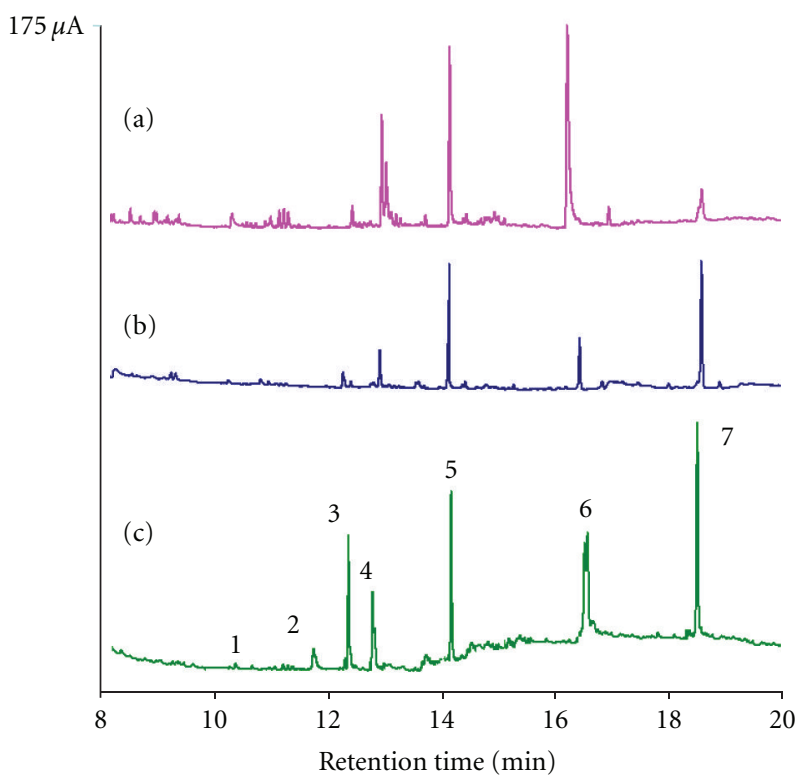

FIGURE 5: PAHs extraction chromatograms of (a) SPE extract of $20 \mathrm{ng} / \mathrm{mL}$ spiked ultrapure water sample (b) $2 \mu \mathrm{g} / \mathrm{mL}$ standard chromatogram (without extraction) and (c) D- $\mu$-SPE-GCFID of $20 \mathrm{ng} / \mathrm{mL}$ spiked water sample. Peak identification: (1) Naphthalene, (2) Biphenyl, (3) Acenaphthene, (4) Fluorene, (5) Phenanthrene, (6) Fluoranthene, (7) Pyrene.

that use commercial sorption materials. The method was successfully applied to the determination of PAHs in real water samples with promising results. 


\section{Acknowledgment}

The authors gratefully acknowledge the Deanship of Scientific Research of KFUPM for the financial support given to this project (Project no. FT100034).

\section{References}

[1] R. Lakshminarayanan, J. S. Joseph, R. M. Kini, and S. Valiyaveettil, "Structure-function relationship of avian eggshell matrix proteins: a comparative study of two major eggshell matrix proteins, ansocalcin and OC-17," Biomacromolecules, vol. 6, no. 2, pp. 741-751, 2005.

[2] S. Suzuki, "Black tea adsorption on calcium carbonate: a new application to chalk powder for brown powder materials," Colloids and Surfaces A, vol. 202, no. 1, pp. 81-91, 2002.

[3] G. D. Nessim, M. Seita, D. L. Plata et al., "Precursor gas chemistry determines the crystallinity of carbon nanotubes synthesized at low temperature," Carbon, vol. 49, no. 3, pp. 804-810, 2011.

[4] Y. Zou, H. Yin, Q. Tan, Y. Chen, G. Lv, and X. Hou, "Polycyclic aromatic hydrocarbons (PAHs) pollution recorded in annual rings of gingko (Gingko biloba L.): regression analysis and comparison to other pollutants," Microchemical Journal, vol. 98, no. 2, pp. 303-306, 2011.

[5] B. Wu, R. Zhang, S. P. Cheng, T. Ford, A. M. Li, and X. X. Zhang, "Risk assessment of polycyclic aromatic hydrocarbons in aquatic ecosystems," Ecotoxicology, vol. 20, no. 5, pp. 1124 1130, 2011.

[6] Y. W. Hong, D. X. Yuan, Q. M. Lin, and T. L. Yang, "Accumulation and biodegradation of phenanthrene and fluoranthene by the algae enriched from a mangrove aquatic ecosystem," Marine Pollution Bulletin, vol. 56, no. 8, pp. 1400-1405, 2008.

[7] P. A. H. Westley, D. E. Schindler, T. P. Quinn, G. T. Ruggerone, and R. Hilborn, "Natural habitat change, commercial fishing, climate, and dispersal interact to restructure an Alaskan fish metacommunity," Oecologia, vol. 163, no. 2, pp. 471-484, 2010.

[8] K. Opuene, I. E. Agbozu, C. C. Iwuozor, and L. E. Ekeh, "Identification of perylene in sediments: occurrence and diagenetic evolution," International Journal of Environmental Science and Technology, vol. 4, no. 4, pp. 457-462, 2007.

[9] P. Boffetta, N. Jourenkova, and P. Gustavsson, "Cancer risk from occupational and environmental exposure to polycyclic aromatic hydrocarbons," Cancer Causes and Control, vol. 8, no. 3, pp. 444-472, 1997.

[10] H. Rubin, "Synergistic mechanisms in carcinogenesis by polycyclic aromatic hydrocarbons and by tobacco smoke: a bio-historical perspective with updates," Carcinogenesis, vol. 22, no. 12, pp. 1903-1930, 2001.

[11] H. Uppstad, G. H. Osnes, K. J. Cole, D. H. Phillips, A. Haugen, and S. Mollerup, "Sex differences in susceptibility to PAHs is an intrinsic property of human lung adenocarcinoma cells," Lung Cancer, vol. 71, no. 3, pp. 264-270, 2011.

[12] WHO, Guidelines for Drinking Water Quality, WHO, Geneva, Switzerland, 3rd edition, 2006.

[13] U.S. EPA. National Primary Drinking Water Standards, 2003, http://www.epa.gov/safewater.

[14] E.U. Directive 2008/105/EC, 2008, Official Journal of the European Communities L-348/84 (24th December, 2008), Council Directive (16th December, 2008) on environmental quality standards for water policy.
[15] N. Li and H. K. Lee, "Solid-phase extraction of polycyclic aromatic hydrocarbons in surface water: negative effect of humic acid," Journal of Chromatography A, vol. 921, no. 2, pp. 255-263, 2001.

[16] Y. Y. Zhou, X. P. Yan, K. N. Kim, S. W. Wang, and M. G. Liu, "Exploration of coordination polymer as sorbent for flow injection solid-phase extraction on-line coupled with highperformance liquid chromatography for determination of polycyclic aromatic hydrocarbons in environmental materials," Journal of Chromatography A, vol. 1116, no. 1-2, pp. 172178, 2006.

[17] G. A. Junk and J. J. Richard, "Organics in water: solid phase extraction on a small scale," Analytical Chemistry, vol. 60, no. 5, pp. 451-454, 1988.

[18] M. Rezaee, Y. Assadi, M. R. Milani Hosseini, E. Aghaee, F. Ahmadi, and S. Berijani, "Determination of organic compounds in water using dispersive liquid-liquid microextraction," Journal of Chromatography A, vol. 1116, no. 1-2, pp. 1-9, 2006.

[19] S. Lundstedt, B. Van Bavel, P. Haglund, M. Tysklind, and L. Öberg, "Pressurised liquid extraction of polycyclic aromatic hydrocarbons from contaminated soils," Journal of Chromatography A, vol. 883, no. 1-2, pp. 151-162, 2000.

[20] G. M. Titato and F. M. Lanças, "Comparison between different extraction (LLE and SPE) and determination (HPLC and capillary-LC) techniques in the analysis of selected PAHs in water samples," Journal of Liquid Chromatography and Related Technologies, vol. 28, no. 19, pp. 3045-3056, 2005.

[21] P. K. Wong and J. Wang, "The accumulation of polycyclic aromatic hydrocarbons in lubricating oil over time-a comparison of supercritical fluid and liquid-liquid extraction methods," Environmental Pollution, vol. 112, no. 3, pp. 407415, 2001.

[22] H. Bagheri, E. Babanezhad, and A. Es-haghi, "An aniline-based fiber coating for solid phase microextraction of polycyclic aromatic hydrocarbons from water followed by gas chromatography-mass spectrometry," Journal of Chromatography A, vol. 1152, no. 1-2, pp. 168-174, 2007.

[23] R. B. Gomes, R. Nogueira, J. M. Oliveira, J. Peixoto, and A. G. Brito, "Determination of total and available fractions of PAHs by SPME in oily wastewaters: overcoming interference from NAPL and NOM," Environmental Science and Pollution Research, vol. 16, no. 6, pp. 671-678, 2009.

[24] X. Yan, D. Wu, H. Peng, K. Ding, C. Duan, and Y. Guan, "Array capillary in-tube solid-phase microextraction: a rapid preparation technique for water samples," Journal of Chromatography A, vol. 1244, pp. 69-76, 2012.

[25] B. Kolahgar, A. Hoffmann, and A. C. Heiden, "Application of stir bar sorptive extraction to the determination of polycyclic aromatic hydrocarbons in aqueous samples," Journal of Chromatography A, vol. 963, no. 1-2, pp. 225-230, 2002.

[26] J. F. Liu, G. B. Jiang, Y. G. Chi, Y. Q. Cai, Q. X. Zhou, and J. T. $\mathrm{Hu}$, "Use of ionic liquids for liquid-phase microextraction of polycyclic aromatic hydrocarbons," Analytical Chemistry, vol. 75, no. 21, pp. 5870-5876, 2003.

[27] R. Lakshminarayanan, X. J. Loh, S. Gayathri et al., "Formation of transient amorphous calcium carbonate precursor in quail eggshell mineralization: an in vitro study," Biomacromolecules, vol. 7, no. 11, pp. 3202-3209, 2006.

[28] J. Yu, M. Lei, and B. Cheng, "Facile preparation of monodispersed calcium carbonate spherical particles via a simple precipitation reaction," Materials Chemistry and Physics, vol. 88, no. 1, pp. 1-4, 2004. 
[29] C. Wang, C. He, Z. Tong, X. Liu, B. Ren, and F. Zeng, "Combination of adsorption by porous $\mathrm{CaCO}_{3}$ microparticles and encapsulation by polyelectrolyte multilayer films for sustained drug delivery," International Journal of Pharmaceutics, vol. 308, no. 1-2, pp. 160-167, 2006.

[30] J. L. Arias, K. Mann, Y. Nys, J. M. G. Ruiz, and M. S. Fernández, "Eggshell growth and matrix macromolecules," in Handbook of Biomineralization: Biological Aspects and Structure Formation, E. Bäuerlein, Ed., Wiley-VCH, GmbH, Weinheim, Germany, 2008.

[31] E. Loste, R. M. Wilson, R. Seshadri, and F. C. Meldrum, "The role of magnesium in stabilising amorphous calcium carbonate and controlling calcite morphologies," Journal of Crystal Growth, vol. 254, no. 1-2, pp. 206-218, 2003.

[32] H. Tong, W. Ma, L. Wang, P. Wan, J. Hu, and L. Cao, "Control over the crystal phase, shape, size and aggregation of calcium carbonate via a L-aspartic acid inducing process," Biomaterials, vol. 25, no. 17, pp. 3923-3929, 2004.

[33] F. Busetti, A. Heitz, M. Cuomo, S. Badoer, and P. Traverso, "Determination of sixteen polycyclic aromatic hydrocarbons in aqueous and solid samples from an Italian wastewater treatment plant," Journal of Chromatography A, vol. 1102, no. 1-2, pp. 104-115, 2006.

[34] Y. N. Hsieh, P. C. Huang, I. W. Sun et al., "Nafion membranesupported ionic liquid-solid phase microextraction for analyzing ultra trace PAHs in water samples," Analytica Chimica Acta, vol. 557, no. 1-2, pp. 321-328, 2006.

[35] P. Popp, C. Bauer, and L. Wennrich, "Application of stir bar sorptive extraction in combination with column liquid chromatography for the determination of polycyclic aromatic hydrocarbons in water samples," Analytica Chimica Acta, vol. 436, no. 1, pp. 1-9, 2001.

[36] L. Oliferova, M. Statkus, G. Tsysin, O. Shpigun, and Y. Zolotov, "On-line solid-phase extraction and HPLC determination of polycyclic aromatic hydrocarbons in water using fluorocarbon polymer sorbents," Analytica Chimica Acta, vol. 538, no. 1-2, pp. 35-40, 2005.

[37] Z. C. Zeledón-Toruño, C. Lao-Luque, F. X. C. de las Heras, and M. Sole-Sardans, "Removal of PAHs from water using an immature coal (leonardite)," Chemosphere, vol. 67, no. 3, pp. 505-512, 2007. 

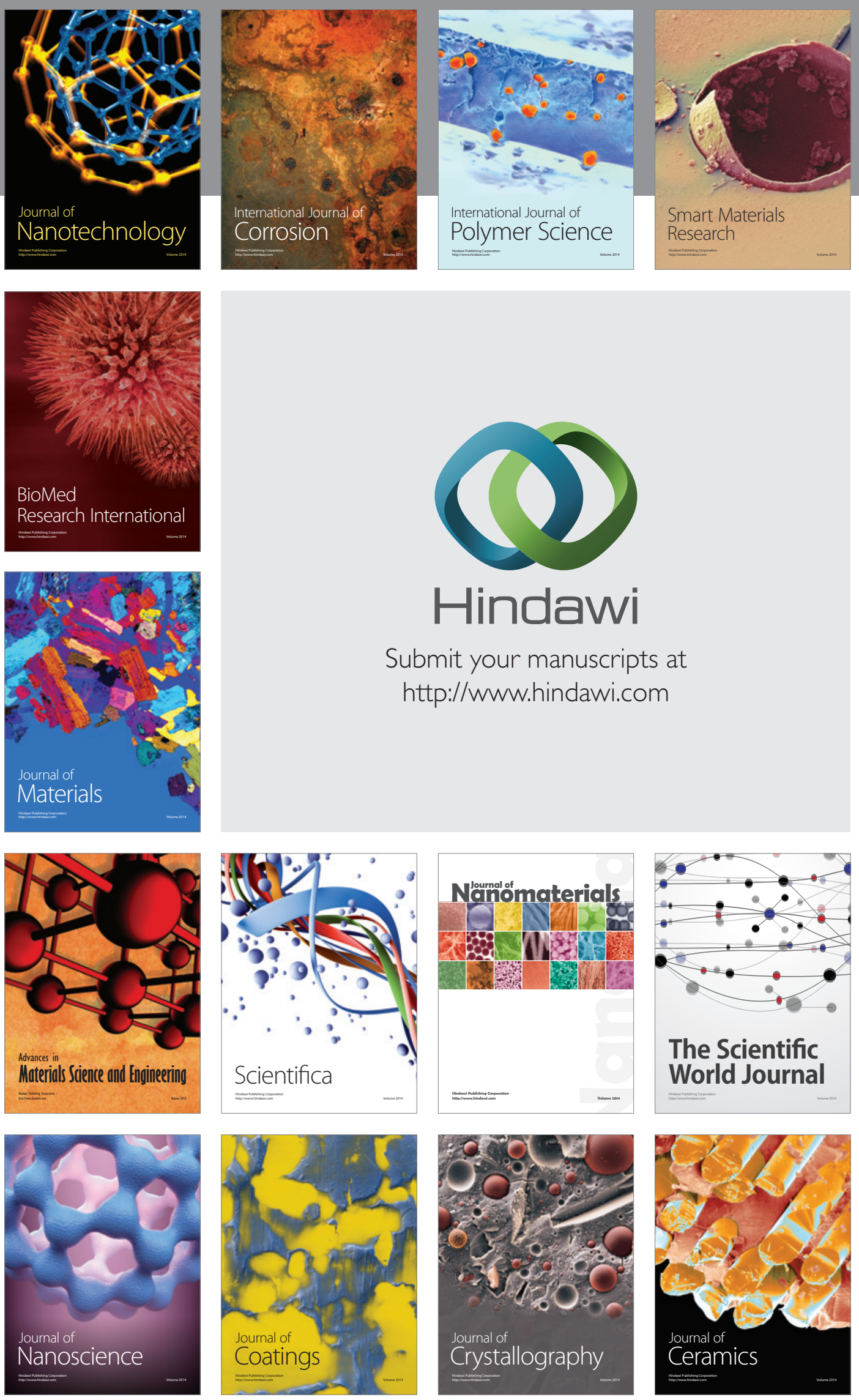

The Scientific World Journal

Submit your manuscripts at

http://www.hindawi.com

\section{World Journal}

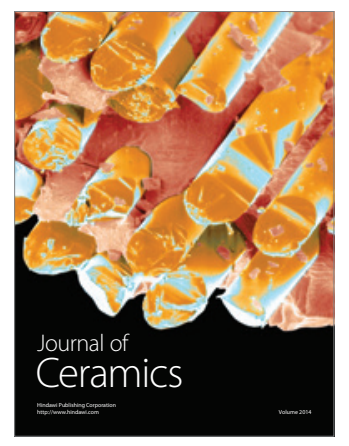

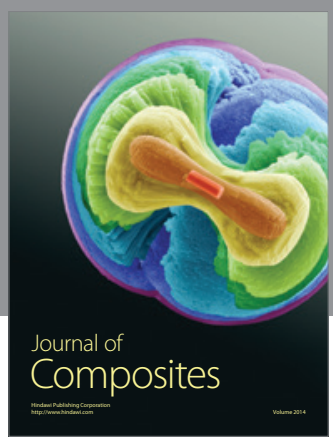
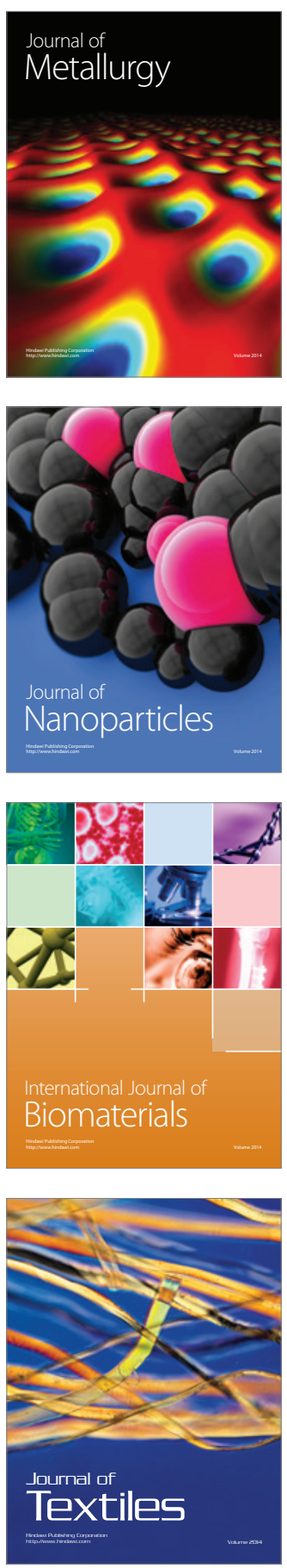